\title{
PRE-SERVICE TEACHERS' SELF-EFFICACY, ATTITUDES AND ACADEMIC PERFORMANCE WITH REGARD TO UNDERGRADUATE RESEARCH MODULES
}

\author{
J. West \\ Department of Early Childhood Education \\ University of Pretoria \\ Pretoria, South Africa \\ e-mail: joyce.west@up.ac.za \\ C. Meier \\ Department of Early Childhood Education \\ University of South Africa \\ Pretoria, South Africa \\ e-mail: meierc@unisa.ac.za
}

\section{ABSTRACT}

The study investigated the significant role that self-efficacy and attitude play in determining preservice teachers' performance within research modules at HEls. Almost 90 per cent of final year education students $(n=128)$ at private HEls, emphasise their dislike for research. They also express their struggle in understanding research modules and how the research modules in their training relate to the teaching profession. This concurrent mixed-method study uses both qualitative and quantitative research to help explain the findings regarding pre-service teachers' apprehensions and challenges relating to research modules. The study also determines preservice teachers' self-efficacy and attitude by administering a survey before the commencement of the research methodology module and qualitative questionnaire upon completion of the research module. By determining pre-service teachers' self-efficacy and attitude, the effectiveness of the research modules is also determined. The relationship between pre-service teachers' selfefficacy, attitude and research module performance as an aspect of the B.Ed. Foundation Phase education curriculum is established. The generic nature of research methodology modules within the B.Ed. curriculum allows this case study's findings to be useful to any other discipline's research methodology modules at other HEls. This study adds to the advancement of institutional research across HEls and motivates interdisciplinary collaboration across South Africa.

Keywords: attitude, performance, research module, self-efficacy, social persuasion, workintegrated learning (WIL)

\section{INTRODUCTION}

The benefits of future teachers getting research method exposure are undeniable; nonetheless, 
many students do not feel the same (Lombard and Klopper 2015, 1). Many students regard research modules as "complex and strenuous" (Lombard and Klopper 2015, 1). According to Li $(2012,154)$ some students even develop a "phobia" towards academic subjects in which they feel anxious and uncomfortable when having to deal with research. Students' high failure rates, lack of interest and "antagonistic views" lead to various challenges that lecturers face (Lombard and Klopper 2015, 1). Macheski, Buhrmann, Lowney and Bush $(2008,44)$ as well as Schutz et al. $(1998,302)$ opine that these negative "research module perceptions" are due to high failure rates and frustration, since research modules are considered extremely difficult. The main challenge lecturers' face includes 'positively shaping students' attitudes, learning and achievement in the field of research methods, as these are fundamental in sustaining future quality research outputs, especially in Education” (Lombard and Klopper 2015, 1).

At a particular private HEI, two research methodology modules are included within the B.Ed. curriculum. The first research methodology module comprises of theoretical knowledge regarding research (critical thinking, analysis and synthesis) and research methods (e.g. the research cycle and implementation of various research designs). The second research methodology module concentrates on research related skills such as analysing academic articles and writing a literature review, in addition to drafting a research proposal related to an educational problem. The existing literature on negative student attitudes and low self-efficacy towards research methodology modules at undergraduate level served as the motivation and rationale of this study. Investigation into students' beliefs, attitudes and self-efficacy regarding their research methodology modules at a private HEI was based on Van der Linden's (2012, 18) belief about the importance of taking pre-service teachers' attitudes and preconceptions (for example self-efficacy) into consideration when introducing them to research methodology modules. Van der Linden $(2012,18)$ opines that students' preconceptions (such as self-efficacy) of research might influence their attitude and behaviour towards research methodology modules and research practices.

\section{Influence of students' attitudes and self-efficacy on academic achievement}

The influence of attitude and self-efficacy on academic performance is a highly deliberated topic in the literature. According to $\operatorname{Li}(2012,157)$ past literature shows a strong relationship between self-efficacy and academic achievement, whereas the influence of attitude on academic achievement is somewhat undecided due to a variety of variables, such as the sample selection that has influenced previous studies. However both attitude and self-efficacy of pre-service teachers have been deemed influential in research-methodology related modules. 


\section{Attitude}

Fishbein $(1967,257)$ conceptualised the term attitude as "learned predispositions to respond to an object or class of objects in a favourable or unfavourable way". Guthrie and Knowles (2001, 161) refer to attitude as the "liking of a task" and Guthrie and Wigfield $(2000,405)$ as "affective factors ... initiated by a motivational state". In this study, attitude is specifically defined as preservice teachers' liking or disliking of (attitude) an undergraduate research methodology module.

According to Fishbein and Ajzen $(1975,14)$, the value-expectancy model argues that attitude will determine behaviour, that can affect outcome. Based on the value-expectancy model, an individual has an attitude towards an object (e.g. the research methodology module in this case) by evaluating it; the person then decides whether to be positive or negative towards it. Fishbein (cited in Li 2012, 156) then further argues that a person's intentions to engage with the object (e.g. the research methodology module) could be determined by their positive or negative attitude. McKenna $(2001,140)$ also developed a model on attitude that follows the belief that attitude is affected by "the object itself" (e.g. the research methodology module) and a "normative nature" (e.g. how a fellow student views the research module). Both the models of Fishbein and Ajzen $(1975,14)$ and McKenna $(2001,140)$ regard attitude as a significant predictor of behaviour and in this case academic performance within the undergraduate research module.

According to $\operatorname{Li}(2012,156)$ research has illustrated a positive correlation between attitude and academic performance. A more positive attitude towards an academic subject creates the possibility for higher academic performance. However, there are researchers, such as Van der Linden $(2012,6)$ and Mickelson $(1990,55)$ who argue that there are too many variables to consider. Variables such as sample selection have affected previous studies that attempted to provide evidence of attitude and academic performance's predictive nature. Therefore, the relationship between attitude and academic performance argument is not unanimous amongst researchers. Van der Linden $(2012,6)$ opines that insight into these relations could enhance the involvement of student teachers in research activities in teacher education. Hence, further investigation is necessary to confirm and understand the influence attitude has on the development of knowledge demonstrated by pre-service teachers' academic performance. Thus, this study aims to gather more insight into the influences of pre-service teachers' attitude and self-efficacy on academic performance with regard to a research methodology module.

\section{Self-efficacy}

Efficacy is described by the Cambridge dictionary (2019) as the ability to "produce the intended 
result". Self-efficacy therefore relates to a personal belief about their own ability to carry out a particular task successfully. Pajares $(2006,341)$ refers to self-efficacy as the manner in which students judge their own competency or efficacy. Bandura $(1998,51)$ states that perceived selfefficacy serves as a self-regulatory system that influences the choices people make, the amount of effort they apply, their perseverance, vulnerability, adversity and aspirations. According to Bandura (1986a, 1390) human behaviour is comprehensively "regulated by judgments of personal efficacy". Therefore, this study deemed it necessary to investigate pre-service teachers' personal efficacy, referred to as "self-efficacy", parallel to pre-service teachers' attitude. Bandura (cited in Guthrie and Wigfield 2000, 408) further defines self-efficacy as "people's judgements of their capabilities to organise and execute courses of action required to obtain designated types of performances". Bandura (1986b, 361) also refers to Kirsch's definition on self-efficacy as "expectancy for success in achievement situations". In this study, self-efficacy is specifically defined as pre-service teachers' belief in their own abilities with regard to completing an undergraduate research methodology module.

As previously mentioned, self-efficacy has been reported by various researchers to be strongly related to academic achievements (Boakye, Sommerville and Debusho 2014, 191; Lent, Larkin and Brown 1986, 265; Li 2012, 157; Turner, Chandler and Heffer 2009, 343). Li (2012, 154) examined pre-service teachers' (enrolled for a research methodology module) attitude, self-efficacy, effort and academic achievement and found a positive correlation between all four variables. A multiple regression analysis also revealed that both attitude and self-efficacy could significantly predict effort. Nonetheless, the effort failed to predict academic achievement.

\section{Pre-service teachers' attitudes and self-efficacy toward research modules}

Pre-service teachers' attitudes and self-efficacy being influential and possible predictors of their academic performance within research modules were explored during this study.

It is important to note the effect that a student's reading ability will have on their selfefficacy, attitude and their academic performance. According to Burrows and Baillie $(1997,39)$ as well as Lombard and Klopper $(2015,3)$, students experience research components (e.g. vocabulary) as vague, meaningless and difficult to comprehend. Zhao et al. $(2016,226)$ as well as Zhao, Guo and Dynia, $(2013,766)$ suggest that students are inclined to feel anxious when they come across unfamiliar words in reading. Van Kraayenoord and Schneider's $(1999,319)$ study also established that reading achievement was related to higher self-efficacy. Their study states that students with high self-efficacy overcome "difficult reading tasks" diligently by using intellectual strategies effectively (Guthrie and Wigfield 2000, 408; Van Kraayenoord and 
Schneider 1999, 319). Therefore, it can be inferred that students enrolled for research methodology methods will need the necessary reading skills to help them build their level of self-efficacy and in turn overcome difficult research methodology tasks with more ease.

Valle (cited in Li 2012, 155) also found that students with higher self-efficacy were more determined and focused with regard to their academic studies. Therefore, it can be inferred that anxious and fearful behaviour is related to students' perceptions and perceived self-efficacy. Students' perceptions and perceived self-efficacy can influence their behaviour such as having a lack of perseverance, which also leads to avoidance. However, the self-efficacy theory suggests that, it is "perceived inefficacy" that give rise to fearful expectations and avoidance behaviour (Bandura 1986a, 1391). Thus, fearful expectations and avoidance behaviour are according to Bandura (1986a, 1391) due to perceived "coping inefficacy" and not necessarily negative self-efficacy.

Bandura (1986a, 1391) also argues that the self-efficacy theory regards "social persuasion as one means to raise people's beliefs concerning their operative capabilities". Based on Bandura's (1986a, 1391) argument, lecturers can use a form of "social persuasion" such as showing, explaining or demonstrating the benefits of completing a task (such as the research module in this case) to influence students' attitudes and self-efficacy. Bandura (1986a, 1391) further elaborates by stating that social persuasion "can lead students to persuade themselves" about their own self-efficacy and that "corroborates predictions from [the] self-efficacy theory that judgments of efficacy can be influenced by social persuasion".

\section{Social persuasion within the research module}

Social persuasion as part of persuasive communication forms a major strategy to evoke change in beliefs, attitudes, intentions and the behaviour of people (Fishbein and Ajzen 1975, 451).

Social persuasion is defined by the Yale Communication Research Program (cited in Fishbein and Ajzen 1975, 452) as "the process by which an individual [the lecturer in this case] transmits stimuli [usually through lectures] to modify or change the behaviour or attitude of other individuals [the pre-service teachers in this case]". According to Fishbein and Ajzen $(1975,396)$ attitude is determined by a person's belief about the attributes of an "object" (such as the research module in this case) evaluated by him or her. In order to evoke change in a person's attitude about the object, a change in one or more of the beliefs about the object or a change in the evaluation of its attributes need to take place.

The most common strategy to change a person's attitude is by directing or introducing new target beliefs about the object, which are assumed to be determinants of the person's attitude towards the object. According to Petty and Cacioppo $(1986,125)$, attitude change can 
only take place through two routes. The first route takes place when motivation and the ability to evaluate "issue-relevant" opinions of the person is high. During the second route, motivation and/or the ability of a person is low and attitudes are determined by a negative or positive message, such as a persuasive argument. Positive attitude change can only occur if the persuasive argument (thoughts generated by the argument) is predominantly favourable, and would therefore require a strong persuasive message (Petty and Cacioppo 1986, 133).

In this study, pre-service teachers' negative attitudes towards an undergraduate research module was determined and then an attempt to change their attitudes was made by weekly introducing new beliefs in the form of a strong persuasive argument about why research modules are important in the classroom. The new beliefs about research was argued from a Work Integrated Learning (WIL) model as described by the NQF that declares the MRTEQ (DHET 2015, 13). WIL is based on the principle of having authentic learning experiences, such as pre-service teachers learning from the classroom itself. WIL requires "practical learning", learning from and in practice. WIL takes place in schools where pre-service teachers learn from practice by critically observing and reflecting on mentors' actions and lessons within the classroom (DHET 2015, 10, 12).

In this study, the lecturer incorporated and integrated the WIL model within the research module. Every lecture as well as every activity and assignment that the pre-service teachers had to complete included a form of WIL. All the research concepts, methods and theories were explained in relation to Foundation Phase educational research, with its main focus on action research. Each week after a lecture on a specific research concept, the pre-service teachers had to critically observe or identify the research concept in an authentic Foundation Phase classroom. Classroom practices and research principles were aligned by asking pre-service teachers to identify any problem in the classroom and then use the research principles described within their prescribed reading to accurately formulate a research problem statement as well as research questions. During lectures, various classroom examples would be included and discussed. All the activities during the lectures were all education-related. For example, during a lesson on quantitative data analysis pre-service teachers had to bring their own learners' marks to class where each student analysed and inferred meaning from their own authentic classroom data.

\section{RESEARCH DESIGN AND METHODS}

The concurrent mixed method design of this study allowed for quantitative and a qualitative data to be collected at different times within a sixteen-week semester. Both quantitate and qualitative research methods was deemed necessary in order to explore pre-service teachers' 
attitude, self-efficacy and academic achievement with regard to an undergraduate research module. Data was also collected on pre-service teachers' academic performance within the research module.

\section{Research design}

For this study, a mixed-method design was chosen since McMillan and Schumacher (2010, 395) explain that more than one method is sometimes necessary in order to answer all the questions of a study. This study therefore utilised both quantitative and qualitative research methods to gather and analyse data in order to answer the research question. This study too place with both a positivist and an interpretivist paradigm. An interpretivist paradigm was used when pre-service teachers' attitudes, opinions and feelings (i.e. attitude and self-efficacy) were investigated through a qualitative research method (i.e. qualitative questionnaire). The positivist paradigm was utilised when, data was generated "through objective measurements, independent of inferences, such as feelings or opinions", related with quantitative research designs (i.e. survey and correlation tests) (Lombard and Klopper $(2015,4)$.

This study also took place as an institutional case study. An "institutional case study" is a rigorous study within a particular setting (Trochim, Donnelly and Arora 2016, 392), for instance, the unique identity of a private HEI. This case study investigated student's attitude, self-efficacy and performance regarding an undergraduate research module at a private HEI. The HEI utilises a blended mode for learning and teaching through interactive e-Learning, lectures over weekends, and self-study. Majority of the students are Caucasian and Afrikaans home language speakers, with reformed Christian church affiliations. They are also employed as assistant teachers or even full-time teachers at public and private schools. The student body's demographical characteristics are mostly homogeneous. The HEI's study body is therefore not representative of the South African population and can thus be considered a unique case study. Limitations to case studies according to Joubert $(2016,163)$ and McLeod (2017) relate to transferability and generalisation. Case studies can also be very time consuming. Generalisation and transferability in this case was not essential given that this study's purpose related to institutional research. The purpose was to improve the private HEI's research methodology modules while also stimulating and contributing to the cross pollination of research methodology modules in South Africa.

Due to the concurrent mixed-method design of the study, the qualitative findings helped explain the quantitative findings. This design also allowed for the inquiry into different kinds of questions (McMillan and Schumacher 2010, 397). This study had both qualitative and quantitative research questions. 
The following research questions guided the quantitative aspect of the study's investigations:

- What are pre-service teachers' attitudes towards research?

- Are there any correlations between pre-service teachers' attitudes towards research; their performance in the research module and their self-efficacy with regard to doing research?

The following research questions guided the qualitative aspect of the study's investigations:

- What are pre-service teachers' biggest concerns and challenges with regard to the research modules?

- How did pre-service teachers experience their first research module?

- How did the pre-service teachers experience the incorporation of the WIL as a form of social persuasion to improve pre-service teachers' attitudes and self-efficacy?

\section{Research method}

Both quantitative and qualitative data collection methods assisted in answering the research questions of this study. 180 students of a private HEI formed the population of this study. They were all pre-service teachers enrolled for the research methodology module within a B.Ed. curriculum $(\mathrm{N}=180)$. Of the initial 180 students, 135 formed the non-probabilistic sample of this study. Seven surveys were also disregarded due to incompletion. To end with, $128(\mathrm{n}=128)$ surveys and questionnaires formed the final sample of the study.

Because of the non-random selection process, the non-probability sampling technique caused debatable external validity (Trochim et al. 2016, 86). The mostly homogeneous participants of the study can be referred to as "typical" (Trochim et al. 2016, 87) of the private HEI population. As a result, the sample can to an extent represent the whole study body of the private HEI $(\mathrm{N}=1021)$. The homogenous or “typical” type of sampling, strengthened the study's case study design (Babbie and Mouton 2014, 281).

Data was collected as part of a two-fold process. The first part of this study comprised of a quantitative survey completed by students before the commencement of the research methodology module. Once students voluntarily agreed to take part in this study, they completed a Likert scale online survey. The purpose of the survey was to determine students' attitudes and self-efficacy prior to completing the first research methodology module. This study's Likert scale survey consisted of choosing from five options, describing their level of 
attitude and self-efficacy. The survey included questions about pre-service teachers' attitude towards research, the research module and their beliefs about their own research abilities (selfefficacy).

The second part of the study consisted of a qualitative questionnaire which was completed about 16 weeks later by the pre-service teachers at the end of the research methodology module. The qualitative questionnaire was completed in the form of a module evaluation "exit slip", where pre-service teachers were again asked about their experiences and attitudes toward research after completing the first research methodology module, it also asked for any suggestions that they may have that could improve the module. The "exit slips" were completed anonymously to avoid fear of reprisals and the possibility of social desirability.

\section{DATA ANALYSIS AND INTERPRETATION}

The qualitative and quantitative results will be discussed simultaneously in the following sections due to the study's concurrent mixed-method research design.

The keywords in the qualitative and quantitative research questions formed the four main themes of discussion: (1) Pre-service teachers' research attitudes; (2) the influence of WIL to evoke attitude change; (3) pre-service teachers' research self-efficacy and (4) the relationship between pre-service teachers' attitudes, self-efficacy and academic performance. Before the influence of attitude and self-efficacy on academic performance could be determined, the preservice teachers' academic performance in the research module was calculated as a cumulative semester mark.

The mean score was 57, ranging from 0 to 100 with a median of 59 and a standard deviation of 13.6. The minimum score was 14 and the maximum of 84 , resulting in a significant range of 70. The final performance marks of the pre-service teachers are asymmetrically distributed on the bar graph, depicted in Figure 1. The final performance marks graph is skewed to the right of the mean, which shows a slight negatively skewed bell curve with greatest frequency of final performance marks distributed after the mean of 57 per cent. Figure 1 provides a depiction for the distribution of the students' concluding marks for the research module.

With a pass rate requirement of 50 per cent, 73.4 per cent of the enrolled pre-service teachers passed the module and 26.6 per cent failed; thus, 34 pre-service teachers of the sample group failed and have to enrol for the research methodology module again the following year before being able to complete the second research module.

An effect size of 0.47 , significant at 0.001 level was found during a two-sample proportions test indicating a moderate statistically significant difference in pre-service teachers 


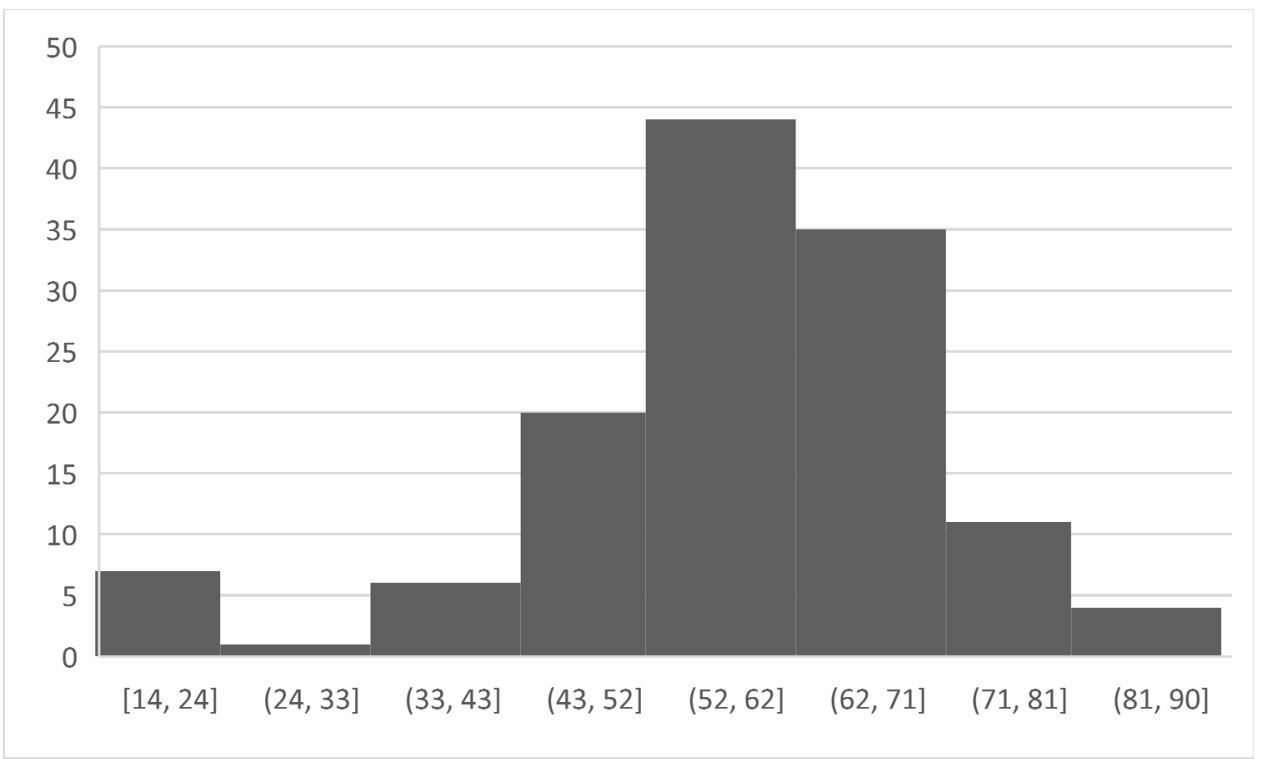

Figure 1: Distribution of participants' final performance of the research module

who passed and failed the research module. The significant difference aligns with Lombard and Klopper's $(2015,1)$ research explaining that pre-service teachers experience high failure rates and regard research modules as "complex and strenuous". After calculating the pre-service teachers' academic performance within the research module as variable, the pre-service teachers' attitudes toward the research module as another variable were determined. The degree to which the participants' attitudes and self-efficacy related to academic performance was established through correlation and will be discussed in the following sections.

\section{Theme 1: Pre-service teachers' attitude towards research methodology modules}

This theme's findings were derived from the quantitative survey done in Week 1 as well as the qualitative questionnaire completed by the pre-service teachers after completion of the module at the end of week 16. The attitude of the pre-service teachers towards the research module was measured, see Figure 2 for the distribution of pre-service teachers' research attitudes in Week 1, ranging on a balanced Likert scale from 1 being extremely negative and pessimistic and 5 being optimistic and excited about the research module.

A mean score of 2.4 and a median of 2 with a standard deviation of 1.04 was calculated for the pre-service teachers' attitudes towards the research module in the beginning. The reported mean provides strong evidence that the pre-service teachers had a negative attitude when they enrolled for the first research module. Only 15.6 per cent of the pre-service teachers' attitudes ranged from being positive (4) to optimistic and excited (5). 50.7 per cent of the pre- 
service teachers' attitude ranged from being extremely negative (1) to negative (2). This finding underscores research done by Lombard and Klopper $(2015,6)$, Macheski et al. $(2008,44)$, Schutz et al. $(1998,302)$ and Van der Linden $(2012,12)$, in terms of negative student attitudes towards research modules. An interesting observation is the 33.5 per cent that said that they do not feel negative or positive; they are unsure how they feel about research. This could either indicate that they feel ambivalent about research and can still be influenced.

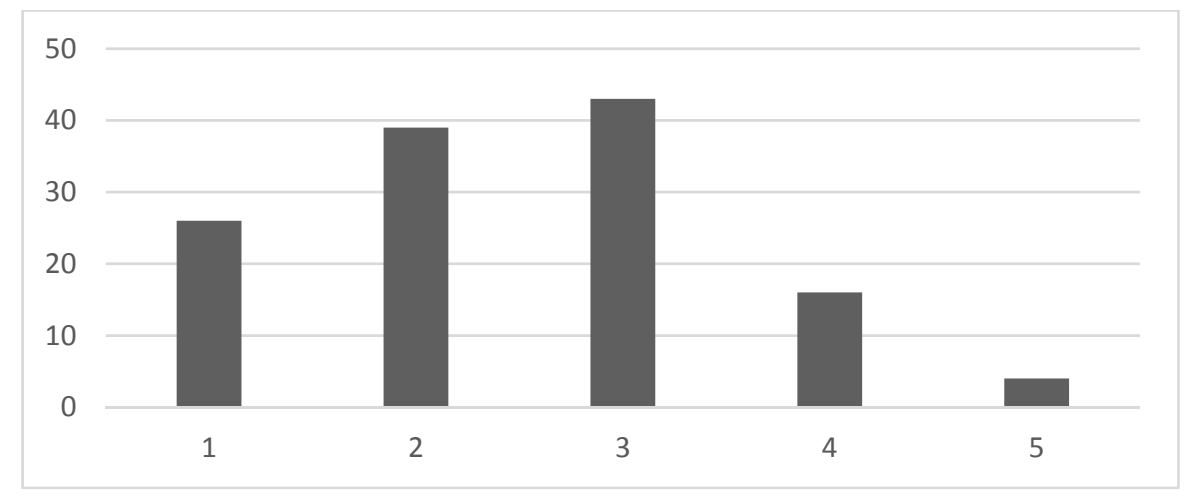

Figure 2: Pre-service teachers' attitude towards the research module

From the qualitative questionnaires completed in week 16, the pre-service teachers' negative attitudes in the beginning of the research module were also evident. As discussed, the preservice teachers experienced serious challenges with the prescribed reading, research vocabulary and concepts. These findings relate to research done by Zhao et al. $(2016,226)$ and Zhao, Guo and Dyni $(2013,766)$ that pre-service teachers are inclined to feel anxious when coming across unfamiliar words within the reading. If pre-service teachers have inadequate vocabulary knowledge it could lead to a lack of comprehension of the written text and thus result in pre-service teachers experiencing anxiety (Hu and Nation 2000, 419; Izaks 2015, 42).

No causality (cause and effect relationship) could be drawn from the quantitative data of this study. However, from the qualitative data it can be inferred that pre-service teachers struggled with both research vocabulary knowledge and comprehending the prescribed reading, which could possibly have been related and have affected their attitude towards the research module. The participants used words such as "confusing", "difficult to comprehend" and "challenging" to describe their experiences with regards to the vocabulary and concepts found within the prescribed textbook. On the qualitative questionnaire most of the pre-service teachers pointed out that they experienced "anxiety" and "stress" and lacked understanding the research vocabulary and concepts. They also explained that it "negatively influenced" their attitude towards research. The pre-service teachers' insufficient comprehension of the research vocabulary and concepts is an unnecessary hindrance when trying to facilitate a positive attitude 
towards research. The majority of the pre-service teachers expressed their lack of confidence and negative attitudes towards the research module in the beginning. However, the majority (i.e. $82 \%$ ) expressed that their attitude and level of confidence changed drastically by the end of the semester.

\section{Theme 2: The Influence of WIL to evoke attitude change}

By using WIL as a form of social persuasion the lecturer wanted to evoke attitude changes towards the research module that the fourth year students were required to enrol for. The importance of integrating WIL into research methodology modules was stressed by the preservice teachers who pointed out in their qualitative questionnaires that the explicit way the research methodology module related to "everyday practice" improved their attitude towards the research module. The "real-life practice-related" activities were described as "motivating", "exciting", "interesting" and a "contribution to becoming a better teacher". One student elaborated by explaining her doubts and fears about the module and how she now feels "excited about the second research module". Another student wrote that she "unexpectedly fell in love with research" because it was made "practical" and made "sense". A student even expressed that she will be "a better teacher in the future" due to the knowledge and skills gained by the module. Therefore, it was evident that WIL as a form of social persuasion was successful in evoking attitude change and making future teachers aware of research-based teaching.

\section{Theme 3: Students' research self-efficacy}

Theme 3's findings were derived from the quantitative survey completed during Week 1. Preservice teachers' self-efficacy with regard to the research module was measured by means of a balanced Likert scale. See Figure 3 for the distribution of pre-service teachers' research selfefficacy, ranging from 1 having no confidence and 5 being very confident about their research abilities.

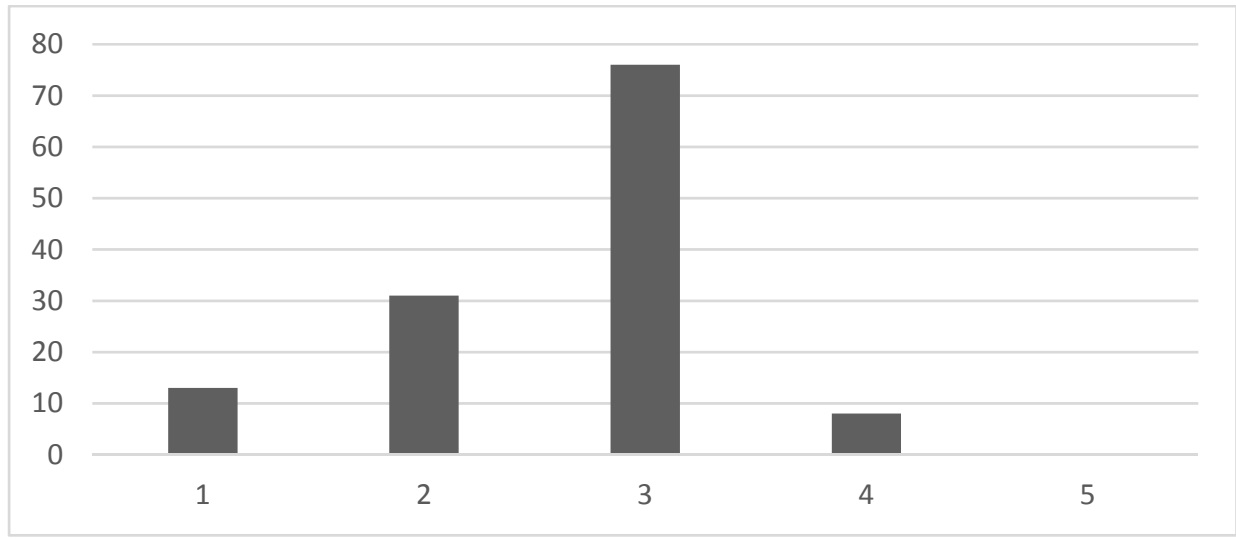


Figure 3: Pre-service teachers' research self-efficacy

A mean score of 2.6 and a median of three with 0.75 standard deviation was calculated, providing strong evidence to believe that pre-service teachers had low levels of self-efficacy and a lack of confidence in their own research abilities when they enrolled for the first research module. Only 6.3 per cent of the pre-service teachers felt good about their own research abilities (4). None of the pre-service teachers indicated that they felt confident about their own research abilities (5). The rest of the pre-service teachers reported (93.7\%) self-efficacy ranging from not being confident (1) to average confidence (3). These findings align with Li's $(2012,154)$ research that some students even develop a "phobia" towards academic subjects and Lombard and Klopper's $(2015,1)$ finding that various lecturers face the challenge of students' lack of interest and "antagonistic views" with regards to research methodology modules. Macheski et al. $(2008,44)$ as well as Schutz et al. $(1998,302)$ opine that these negative "research module perceptions" are due to high failure rates and frustration, since research modules are considered extremely difficult.

\section{Theme 4: The relationship between attitude, self-efficacy and academic performance}

No statistically significant correlation was found between the pre-service teachers' attitudes and their academic performance. Neither was a correlation found between their level of selfefficacy and academic performance. The lack of correlation aligns with Li's $(2012,154)$ study that shows that both attitude and self-efficacy cannot necessarily predict academic achievement. There was however a positive, moderate correlation of .477, at a 0.01 significance level (twotailed) between pre-service teachers' self-efficacy scores and their attitudes towards the research module. It can therefore be inferred that there is a positive and relatively strong correlation between how pre-service teachers feel about their own research abilities and their attitude towards the research methodology module. Both self-efficacy and attitude can therefore also influence one another.

\section{DISCUSSION AND CONCLUSION}

This case study's research investigated a private HEI's pre-service teachers enrolled for a research methodology module for the first time as an aspect of their B.Ed. curriculum. The study considered their attitudes, self-efficacy and academic performance within a research module. The research aimed at determining if any relationships exist between the variables, as well as how improvement can take place within the research methodology modules, to help 
shape future teachers into active, research-based practitioners. The only positive, moderate correlation that was found was between pre-service teachers' self-efficacy levels and their attitudes towards the research methodology module. The concurrent mixed method study also found that pre-service teachers struggle with research vocabulary and concepts as well as comprehending the prescribed reading. These struggles influence their attitude and level of selfefficacy and therefore have serious implications for the teaching of research modules. In the study successful social persuasion of pre-service teachers took place by changing their attitudes from being mostly negative to positive, through the use of WIL. The data showed that preservice teachers experienced a change in attitude towards the research methodology module by the end of the module (Week 16). It can therefore be recommended that when teaching research methodology modules, lecturers should include a form of WIL to make it more "practical", relatable and to improve students' attitude and level of self-efficacy towards the research methodology modules.

This study point out the relationship between pre-service teachers' self-efficacy and attitudes as well as their understanding of the vocabulary and reading comprehension ability with regards to research methodology modules. The relationship between pre-service teachers' reading comprehension skills and vocabulary knowledge could however be further investigated. An apparent association between the pre-service teachers' vocabulary knowledge and their attitude towards research could also further be investigated.

Although this was an institutional case study, the basis of undergraduate research modules allow this study's findings to be relevant to other HEI's and other disciplines. Further research into undergraduate research modules at other HEI can contribute to the advancement of best practices and the progression of institutional research across South Africa. Furthermore, it could promote interdisciplinary collaboration at HEIs.

\section{REFERENCES}

Babbie, E. and J. Mouton. 2014. The practice of social research. Cape Town: Oxford University Press.

Bandura, A. 1986a. Fearful expectations and avoidant actions as coeffects of perceived self-inefficacy. American Psychologist 41(1): 1389-1391.

Bandura, A. 1986b. Social foundations of thought and action: A social cognitive theory. Englewood Cliffs: Prentice-Hall.

Bandura, A. 1998. Personal and collective efficacy in human adaptation and change. In Advances in psychological science: Personal, social and cultural aspects, ed. J. G. Adair, D. Belanger and K. L. Dion, 51-71. Hove: Psychology Press.

Boakye, N., J. Sommerville and L. Debusho. 2014. The relationship between socio-afftive factors and reading proficiency: Implications for Tertiary reading instruction. Journal for Language Teaching 48(1): 173-213.

Burrows, E. and L. Baillie. 1997. A strategy for teaching research to adult Branch Diploma students. 
Nurse Education Today 35(1): 39-45.

Cambridge dictionary. 2019. Efficacy. 5 June 2019. https://dictionary.cambridge.org/dictionary/ english/efficacy

Department of Higher Education and Training. 2015. National Qualifications Framework Act (67 of 2008): Revised Policy on the Minimum Requirements for Teacher. Discussion Paper. Government Gazette 38487, Notice 596, 19 February 2015: 3. Pretoria: Government Printer.

DHET see Department of Higher Education and Training.

DoE see Department of Education.

Fishbein, M. 1967. Readings in attitude theory and measurement. New York: Kohn Wiley \& Sons.

Fishbein, M, and I. Ajzen. 1975. Belief, attitude, intention, and behavior: An introduction to theory and Research. MA: Addison-Wesley.

Guthrie, J. T. and K. Knowles. 2001. Promoting reading motivation. In Literacy and motivation: Reading engagement in individuals and groups, ed. L. Verhoeven, C. E. Snow, 159-176. Mahwah: Erlbaum.

Guthrie, J. T. and A. Wigfield. 2000. Engagement and motivation in reading. In Handbook of reading research, ed. M. L. Kamil, P. B. Mosenthal, P. D. Pearson and R. Barr, 403-422. New York: Longman.

HESA see Higher Education South Africa.

$\mathrm{Hu}, \mathrm{M}$. and I. S. P. Nation. 2000. Unknown vocabulary density and reading comprehension. Reading in a Foreign Language 13(1): 403-430.

Izaks, J. A. 2015. Study of the effects of an undergraduate vocabulary programme on vocabulary development and academic literacy. Master's thesis, University of South Africa (Unisa).

Joubert, I. 2016. Gevallestudie: Riglyne vir ontwerp en uitvoering van die navorsing. In Navorsing: ' Gids vir die beginnnernavorser, ed. I. Joubert, C. Hartell and K. Lombard, 131-165. Pretoria: Van Schaik.

Lent, R. W., K. C. Larkin and S. D. Brown. 1986. Self-efficacy in the prediction of academic performance and perceived career options. Journal of Counselling Psychology 33(3): 265-269.

Li, L. K. Y. 2012. A study of the attitude, self-efficacy, effort and academic achievement of CityU students towards research methods and statistics. Discovery 1(1): 154-183.

Lombard, B. J. J. and M. Klopper. 2015. Undergraduate student teachers' views and experiences of a compulsory course in Research Methods. South African Journal of Education 35(1): 1-14.

Macheski, G. E., J. Buhrmann, K. S. Lowney and M. E. Bush. 2008. Overcoming student disengagement and anxiety in theory, methods, and statistics courses by building a community of learners. Teaching Sociology 36(1): 42-48.

McKenna, M. C. 2001. Development of reading attitudes. In Literacy and motivation, ed. L. Verhoeven and C. E. Snow, 135-176. Mahwah: Lawrence Erlbaum.

McLeod, S. 2017. Case study method. Simply Psychology. 20 January 2017. http://www.simply psychology.org/case-study.html

McMillan, J. and S. Schumacher. 2010. Research in education: Evidence-based inquiry. Boston: Pearson.

Mickelson, R. A. 1990. The attitude-achievement paradox among black adolescents. Sociology of Education 63(1): 44-61.

Pajares, F. 2006. Self-efficacy during childhood and adolescence: Implications for teachers and partners. In Self-efficacious beliefs of adolescents, ed, F. Pajares and T. Urden, 339-367. Greenwhich: Information Age.

Petty, R. E. and J. T. Cacioppo. 1986. The elaboration likelihood model of persuasion. Advances in Experimental Social Psychology 19: 123-205. 
Schutz, P. A., L. M. Drogosz, V. E. White and C. Distefano. 1998. Prior knowledge, attitude, and strategy use in an Introduction to Statistics Course. Learning and Individual Differences 10(4): 291-308.

Trochim, W. M., J. P. Donnelly and K. Arora. 2016. Research methods: The essential knowledge base. Boston: Cengage Learning.

Turner, E. A., M. Chandler and R. W. Heffer. 2009. The influence of parenting styles, Achievement motivation and self-efficacy on academic performance in college students. Journal of College Student Development 50(3): 337-346.

Van der Linden, W. A. 2012. Design-based approach to introducing student teachers in conducting and using research. PhD dissertation, Eindhoven University of Technology Library, 2012.

Van Kraayenoord, C. E. and W. E. Schneider. 1999. Reading achievement, metacogition, self-concept and interest: A study of German students in Grade 3 and 4. Journal of Psychology of Education $\mathrm{XIV}(3)$ : 305-324.

Zhao, A., Y. Guo, C. Biales and A. Olszewski. 2016. Exploring learner factors in second language (L2) incidental vocabulary acquisition through reading. Reading in a Foreign Language 28(2): 224245.

Zhao, A., Y. Guo and J. Dynia. 2013. Foreign language reading anxiety: Chinese as a foreign language in the United States. The Modern Language Journal 97(3): 764-778. 